\title{
Abgabenordnung (Auszug)
}

\section{Steuerschuldverhältnis}

\section{§ 39 (Zurechnung)}

(1) Wirtschaftsgüter sind dem Eigentümer zuzurechnen.

(2) Abweichend von Absatz 1 gelten die folgenden Vorschriften:

1. Übt ein anderer als der Eigentümer die tatsächliche Herrschaft über ein Wirtschaftsgut in der Weise aus, dass er den Eigentümer im Regelfall für die gewöhnliche Nutzungsdauer von der Einwirkung auf das Wirtschaftsgut wirtschaftlich ausschließen kann, so ist inm das Wirtschaftsgut zuzurechnen. Bei Treuhandverhältnissen sind die Wirtschaftsgüter dem Treugeber, beim Sicherungseigentum dem Sicherungsgeber und beim Eigenbesitz dem Eigenbesitzer zuzurechnen.

2. Wirtschaftsgüter, die mehreren zur gesamten Hand zustehen, werden den Beteiligten anteilig zugerechnet, soweit eine getrennte Zurechnung für die Besteuerung erforderlich ist. 